\title{
Measuring sexual behaviour in the era of HIV/AIDS: the experience of Demographic and Health Surveys and similar enquiries
}

\author{
S L Curtis, E G Sutherland
}

Sex Transm Infect 2004;80(Suppl II):ii22-ii27. doi: 10.1136/sti.2004.011650

\begin{abstract}
Objectives: To review the sexual behaviour data collected in the Demographic and Health Surveys (DHS) and other similar national surveys from the perspective of data quality.

Methods: Two indicators of premarital and higher risk sexual behaviour were analysed for 31 surveys in 10 countries in sub-Saharan Africa and Latin America and the Caribbean. The analysis focused on the internal consistency of trends and gender differences in the reported indicators.

Results: The authors found fluctuating trends in premarital sex in sub-Saharan Africa but consistent increases in Latin America and the Caribbean. Changes in questionnaire design do not seem to contribute to these trends and there is evidence that the increase in premarital sex is genuine in Latin America. Trends in sex with non-spousal, non-cohabiting partners show large fluctuations and inconsistencies between surveys in some countries but not others. Men are consistently more likely to report non-marital sexual partners than women and unmarried women are less likely than unmarried men to report casual partners. Conclusions: Surveys are potentially a valuable source of information on sexual behaviour but there are sufficient grounds for concern to warrant considerable caution in the use of survey data to monitor trends in sexual behaviour. Survey findings must be evaluated carefully and interpreted in the context of other available information. These results caution against placing heavy emphasis on short term changes in sexual behaviour between individual surveys and highlight the need for attention to quality in data collection.

See end of article for authors' affiliations

D emand for data on sexual behaviour has increased with the spread of HIV and the consequent need for data to inform and evaluate HIV prevention activities, many of which focus on promoting safer sexual practices. Early concerns that data on sexual behaviour cannot be collected in household surveys have proved unfounded: response rates for questions on sexual behaviour are typically high in the Demographic and Health Surveys (DHS) and other similar surveys, ${ }^{1-3}$ and findings of the UNAIDS field test of the HIV/ AIDS Prevention Indicators Survey were generally encouraging concerning their feasibility. ${ }^{4}$ Nevertheless, justified concerns remain about the quality of such data. Analyses of the quality of self-reported sexual behaviour have found evidence of several problems including underreporting of ever having had sex among young unmarried respondents, underreporting of the number of partners (particularly by women), possible exaggeration of the number of partners by some young unmarried men, inconsistencies between age at first sex and age at first birth, and inconsistencies in age at first sex reported by a birth cohort over time. ${ }^{2-9}$

To date, the DHS programme has conducted more than 170 surveys in about 70 countries throughout Africa, Asia, the Near East, Latin America, and the Caribbean ${ }^{10}$ and most of these surveys include at least some data on sexual behaviour. Other survey programmes such as the Reproductive Health and Young Adult Surveys conducted by the US Centers for Disease Control and Prevention (CDC) also collect data on sexual behaviour, and recent initiatives such as Sexual Behaviour Surveys (SBS) and AIDS Indicator Surveys add to the range of survey options available for collecting sexual behaviour data. Collectively these surveys constitute an enormous potential source of information on sexual behaviour to inform HIV programmes, but their utility is dependent on the quality of data collected. The objective of this paper is to review the sexual behaviour data collected in these surveys to date from the perspective of the quality of the data. The assessment of the quality of the data is limited by the fact that we do not know the "true" behaviour. We therefore focus on one dimension of data quality-the internal consistency of the data. Particular emphasis will be placed on the internal consistency of data for trend analysis and gender differences in reporting of sexual behaviour.

\section{DATA AND METHODS}

The primary source of data for this study is the DHS. The DHS has been collecting information on sexual behaviour since its inception in 1984. Initially, data were collected in the context of understanding fertility and were collected only from women aged 15-49 years, but the rise of AIDS as a public health crisis led the DHS to include more questions on sexual behaviour and to increasingly include surveys of men. The age range for male surveys varies but is most often 15-59 years or 15-54 years. The exact wording and structure of questions on sexual behaviour have evolved significantly over time. ${ }^{11-13}$ However, there has been a trend toward increasing consensus and standardisation of the survey instruments both in the DHS and in other similar surveys (S Curtis, unpublished paper presented at the WHO, UNAIDS, MEASURE Evaluation and the London School of Hygiene and Tropical Medicine Technical Meeting on Measurement of Sexual Behaviour in the Era of HIV/AIDS, London, 4-6 September 2003).

We selected a subset of 31 DHS surveys in 10 countries for this analysis. The countries selected are: Ghana, Kenya, Tanzania, Uganda, Zambia, and Zimbabwe in sub-Saharan

Abbreviations: CDC, Centers for Disease Control; DHS, Demographic and Health Surveys; SBS, Sexual Behaviour Survey. 
Africa, and Colombia, the Dominican Republic, Haiti, and Peru in Latin America and the Caribbean. These countries were selected because they have conducted multiple DHS surveys and cover two separate regions of the world, thus providing a regional comparative perspective. Countries in Asia and North Africa/Near East could not be included because DHS surveys there do not include questions on sexual behaviour. In the few Asian countries that have collected sexual data (for example, Cambodia and Nepal) virtually no respondents reported premarital or extramarital sexual relations. The surveys we did select cover the evolution of the questions on sexual behaviour during the relevant period and therefore allow us to review the potential effect of changing question wording on the indicators and to examine the stability and plausibility of trends in sexual behaviour over time. The exact content of the surveys varies slightly so different subsets of surveys are included in different tables, dependent on the availability of specific data in each survey.

In addition to the DHS surveys we use three SBS conducted in Zambia in 1998, 2000, and 2003. The SBS is much shorter than the DHS and collects more detailed information on sexual behaviour. In the 1998 Zambia SBS, a fairly detailed complete partner history was collected for the 12 months before the survey. ${ }^{14}$ The 2000 and 2003 Zambia SBS used a shorter partial partner history for the three most recent partners in the previous 12 months, similar to the most recent DHS surveys. ${ }^{15}$ Because the survey is relatively short and focuses primarily on sexual behaviour, the questions on sex come early in the questionnaire compared with the DHS.

The analysis focuses on two indicators of sexual behaviour: the percentage of unmarried respondents aged 15-24 years who report premarital sex in the last 12 months and, of those who had sex in the last 12 months, the percentage who report sex with a non-spousal, non-cohabiting partner during that period. Both of these indicators are standard indicators recommended for monitoring sexual behaviour in the context of HIV/AIDS programmes and as such are of particular global interest. ${ }^{16}$ These indicators were obtained from the MEASURE DHS+ HIV/AIDS Survey Indicators Database. ${ }^{17}$ Additional tabulations were conducted using the DHS standard recode files and SBS data files for selected surveys. For women, sample sizes for the selected surveys vary from 1286 in the 1999 Dominican Republic DHS to 28951 in the 1996 Peru DHS, with sample sizes typically falling in the range 4000-9000 in the DHS surveys and 1500-2000 for the SBS surveys. For men, sample sizes range from 1112 in the 1999 Dominican Republic DHS to 4700 in the 2002 Dominican Republic DHS.

\section{RESULTS}

\section{Premarital sex}

Table 1 shows the percentage of never-married respondents aged 15-24 years who report having had sex in the 12 months preceding each survey. Among women, the percentage reporting premarital sex in the previous year ranges from 5\% in the 1991 Dominican Republic DHS to 49\% in the 1993 Ghana DHS. In general, reporting of premarital sex is more common among women in sub-Saharan Africa than in Latin America and the Caribbean. Among men, the percentage reporting premarital sex in the last year ranges from $24 \%$ in the 1998 Ghana DHS to $65 \%$ in the $1991 / 92$ Tanzania DHS and there are no regional differences, although few surveys of men are available in Latin America.

Men are more likely than women to report premarital sex in the previous 12 months in every country except Ghana. The "excess" reporting of premarital sex among men ranges from 4 percentage points in the 2000/01 Uganda DHS to 44 percentage points in the 1996 Dominican Republic DHS. Underreporting of
Table 1 Percentage of never-married men and women aged 15-24 years who report premarital sex in the last 12 months, selected surveys

\begin{tabular}{|c|c|c|c|}
\hline Country, study year & Men & Women & $\begin{array}{l}\text { Absolute } \\
\text { difference }\end{array}$ \\
\hline \multicolumn{4}{|l|}{ Sub-Saharan Africa } \\
\hline Ghana, 1988 & NA & $40(838)$ & \\
\hline Ghana, 1993 & $46(352)$ & 49 (828) & -3 \\
\hline Ghana, 1998 & $24(494)$ & 31 (979) & -7 \\
\hline Kenya, 1989 & NA & 33 (1607) & \\
\hline Kenya, 1993 & NA & 35 (2084) & \\
\hline Kenya, 1998 & $56(1285)$ & 32 (2079) & 24 \\
\hline Tanzania, 1991/92 & $65(691)$ & 35 (1991) & 30 \\
\hline Tanzania, 1996 & $44(746)$ & $29(1713)$ & 15 \\
\hline Tanzania, 1999 & 57 (1155) & $39(890)$ & 18 \\
\hline Uganda, 1988/89 & NA & 35 (934) & \\
\hline Uganda, 1995 & $33(518)$ & 22 (1129) & 11 \\
\hline Uganda, 2000/01 & $31(603)$ & $27(1446)$ & 4 \\
\hline Zambia DHS, 1992 & NA & $42(1675)$ & \\
\hline Zambia DHS, 1996 & $57(716)$ & 36 (1 1823) & 21 \\
\hline Zambia SBS, 2000 & $36(453)$ & $31(456)$ & 5 \\
\hline Zambia DHS, 2001/2002 & $51(700)$ & 31 (1697) & 20 \\
\hline Zambia SBS, 2003 & 34 (701) & $29(505)$ & 5 \\
\hline Zimbabwe, 1988 & NA & $18(1058)$ & \\
\hline Zimbabwe, 1994 (3) & $38(905)$ & $13(1525)$ & 25 \\
\hline Zimbabwe, 1999 & 34 (1137) & $15(1524)$ & 19 \\
\hline \multicolumn{4}{|c|}{ Latin America and Caribbean } \\
\hline Colombia, 1986 & NA & $8(1557)$ & \\
\hline Columbia, 1990 & NA & $12(2363)$ & \\
\hline Colombia, 1995 & NA & $19(2607)$ & \\
\hline Colombia, 2000 & NA & $28(2805)$ & \\
\hline Dominican Republic, 1991 & NA & $5(1769)$ & \\
\hline Dominican Republic, 1996 & $52(685)$ & $8(1731)$ & 44 \\
\hline Dominican Republic, 2002 & $52(797)$ & $13(4432)$ & 40 \\
\hline Haiti, 1994 & $52(556)$ & $17(1528)$ & 35 \\
\hline Haiti, 2000 & 47 (1207) & 21 (2789) & 26 \\
\hline Peru, 1991/92 & NA & 10 (4553) & \\
\hline Peru, 2000 & NA & 13 (7142) & \\
\hline
\end{tabular}

premarital sex by female respondents looks particularly likely in the 1996 and 2002 Dominican Republic DHS.

Trends in reported premarital sex among women generally fluctuate in sub-Saharan Africa; only in Zambia does there appear to be a consistent trend. In Latin America and the Caribbean the surveys suggest consistent increases in reported premarital sex among women. Much less information on trends in premarital sexual behaviour is available for men but in several countries (for example, Tanzania and Zambia) the data are either erratic or show suspiciously large changes in reported behaviour over a five year period (for example, Ghana).

As there have been relatively few changes in the DHS questions that provide the data for this indicator, changes in questionnaire design are unlikely to be a significant explanatory factor in the observed trends. However, early DHS questionnaires asked unmarried respondents whether they had ever had sex, whereas later DHS questionnaires dropped this question in favour of simply asking respondents the last time they had had sex. Results from an experimental component added to the pretest of the first CDC Young Adult Survey in Mexico in 1985 suggested that the use of the "ever had sex" question tended to produce much lower reporting of premarital sex (L Morris. Personal communication, 2003). Table 2 shows the percentage of never-married women aged 15-24 years who reported ever having had sex in our surveys. These surveys span the evolution of the DHS questionnaire so earlier ones include the "ever had sex" question whereas later ones do not. In the Latin American surveys there has been a steady increase in the percentage of young single women reporting ever having had sex. This does not appear to be linked to the inclusion of the "ever had sex" question because there is a gradual increase over time rather than a 
sudden increase when the "ever had sex" question was dropped. Changes in the age or educational profile of 15-24 year olds between surveys will also affect the percentage who report ever having had sex. For example, in later surveys a larger proportion of 20-24 year olds relative to 15-19 year olds will increase the percentage of 15-24 year olds who report ever having had sex. ${ }^{8}$

The surveys in Africa do not appear to be affected by the inclusion of the "ever had sex" question either. In Zambia two different instruments have been applied (the DHS and SBS). For women, the SBS and DHS provide consistent estimates of premarital sex in the previous year, but the DHS provides higher estimates of premarital sex among men than does the SBS (table 1). Furthermore, the SBS estimates for men are very similar to those obtained for women, whereas the DHS estimates are much higher than the corresponding estimates for women. The reasons for the differences between the SBS and DHS are unclear but could include differences in survey implementation and questionnaire design. In particular, the DHS is a much longer and more general questionnaire than the SBS and the sexual behaviour questions come later in the interview. Therefore, the rapport built up between the interviewer and the respondent at the time the sexual behaviour questions are asked is likely to be quite different which could affect the responses.

We further investigate the plausibility of the observed trends by examining the internal consistency of the data on premarital sex with data on childbearing, contraceptive use, and marriage obtained in different parts of the DHS questionnaires. The third column of table 2 shows the percentage of women aged 15-24 years who experienced a premarital conception resulting in either a live birth or current pregnancy. The DHS does not consistently collect data on pregnancies resulting in spontaneous or induced abortions, and reporting of abortions is poor when it is collected. Therefore, it is not possible to estimate the percentage of women aged 15-24 years who have experienced a premarital conception. The numerator used here is never-married women who are either currently pregnant or have had a live birth, and married women whose first live birth occurred less than seven months after the reported date of first marriage.

Table 2 also shows the percentage of never-married women aged 15-24 years who have ever used a contraceptive method and the median age at first marriage among women age 25-49 years. In African countries, where the surveys show little change in the rate of premarital sex, premarital fertility has decreased or remained about the same, and contraceptive use has generally increased. In Latin American countries, where the surveys show a large increase in the reporting of premarital sex, premarital fertility has either remained the same or increased slightly, and contraceptive use has increased. All countries except Haiti show increases in age at first marriage thereby increasing the period in which young people can engage in premarital sex. Although the magnitude of these changes is slight there is general concordance between indicators. In several countries (Zimbabwe, Dominican Republic, Peru, and earlier surveys in Colombia) the percentage of all 15-24 year olds who experienced a premarital conception is close to and sometimes higher than the percentage of never-married 15-24 year olds who report they have ever had sex. Although these figures are not directly comparable because they are based on different denominators, the relatively high level of premarital pregnancy compared with premarital sex suggests underreporting of premarital sex in these surveys.

\section{Higher risk sex}

Table 3 shows the percentage of respondents who have had sex with a non-spousal, non-cohabiting partner during the

Table 2 Percentage of never-married women aged 15-24 years who have ever had sex, are pregnant or mothers, and have ever used contraception, and median age at first marriage among women aged 25-49 years, selected surveys

\begin{tabular}{|c|c|c|c|c|}
\hline Country, survey year & Had sex & $\begin{array}{l}\text { Pregnant or } \\
\text { mothers* }\end{array}$ & $\begin{array}{l}\text { Ever used } \\
\text { contraception }\end{array}$ & $\begin{array}{l}\text { Median age at } \\
\text { marriage among } \\
\text { women aged 25-49 } \\
\text { yearst }\end{array}$ \\
\hline \multicolumn{5}{|l|}{ Sub-Saharan Africa } \\
\hline Kenya, 1989 & 43.7 & 31.5 & 18.9 & 18.1 \\
\hline Kenya, 1993 & 45.2 & 27.4 & 19.3 & 18.8 \\
\hline Kenya, 1998 & 41.6 & 24.1 & 16.8 & 19.2 \\
\hline Tanzania, $1992 \ddagger$ & 39.8 & 22.7 & 7.4 & 17.9 \\
\hline Tanzania, 1996 & 39.8 & 20.4 & 12.1 & 18.2 \\
\hline Tanzania, 1999 & 43.1 & 16.2 & 14.0 & 18.1 \\
\hline Zambia, $1992 \ddagger$ & 50.8 & 22.4 & 11.5 & 17.4 \\
\hline Zambia, 1996 & 51.6 & 22.6 & 16.8 & 17.7 \\
\hline Zambia, 2001/02 & 50.2 & 25.6 & 19.5 & 17.8 \\
\hline Zimbabwe, 1988 & 22.8 & 18.8 & 9.8 & 18.6 \\
\hline Zimbabwe, 1994 & 18.2 & 20.2 & 10.1 & 18.9 \\
\hline Zimbabwe, 1999 & 20.4 & 21.9 & 12.6 & 19.3 \\
\hline \multicolumn{5}{|l|}{ Latin America and Caribbean } \\
\hline Colombia, $1986 \ddagger$ & 11.4 & 10.6 & 4.8 & 20.8 \\
\hline Colombia, $1990 \ddagger$ & 15.6 & 11.1 & 7.1 & 21.0 \\
\hline Colombia, 1995 & 23.2 & 14.0 & 10.8 & 21.4 \\
\hline Colombia, 2000 & 39.4 & 15.8 & 32.9 & 21.5 \\
\hline Dominican Republic, 1986‡ & 3.8 & 9.4 & 1.2 & 18.5 \\
\hline Dominican Republic, $1991 \mp$ & 6.1 & 5.9 & 4.6 & 19.0 \\
\hline Dominican Republic, 1999 & 11.1 & 8.4 & 5.5 & 19.3 \\
\hline Haiti, 1994 & 21.9 & 8.3 & 7.3 & 20.8 \\
\hline Haiti, 2000 & 25.3 & 7.4 & 10.7 & 20.5 \\
\hline Peru, 1986 & 9.6 & 11.3 & 2.3 & 20.5 \\
\hline Peru, 1992 $\ddagger$ & 13.6 & 11.8 & 8.3 & 21.1 \\
\hline Peru, 2000 & 20.0 & 14.6 & 13.8 & 21.4 \\
\hline
\end{tabular}


Table 3 Percentage of sexually active men and women who report sex with a non-spousal, non-cohabiting partner in the last 12 months, selected surveys

\begin{tabular}{llll}
\hline Country, survey year & Men & Women & $\begin{array}{l}\text { Absolute } \\
\text { difference }\end{array}$ \\
\hline $\begin{array}{l}\text { Sub-Saharan Africa } \\
\text { Kenya, 1998 }\end{array}$ & $47(2766)$ & $22(5881)$ & 25 \\
Tanzania, 1996 & $38(1650)$ & $18(6091)$ & 20 \\
Tanzania, 1999 & $51(2775)$ & $27(3083)$ & 24 \\
Uganda, 1995 & $29(1510)$ & $11(5340)$ & 18 \\
Uganda, 2000/01 & $28(1454)$ & $14(5497)$ & 14 \\
Zambia, DHS 1996 & $49(1490)$ & $23(6119)$ & 26 \\
Zambia, SBS 1998 & $39(1258)$ & $17(1527)$ & 22 \\
Zambia, SBS 2000 & $29(1158)$ & $16(1299)$ & 13 \\
Zambia, DHS 2001/02 & $45(1718)$ & $18(5650)$ & 27 \\
Zambia, SBS 2003 & $25(1542)$ & $13(1663)$ & 12 \\
Zimbabwe, 1999 & $41(1796)$ & $14(4180)$ & 27 \\
Latin America and Caribbean & & $28(8181)$ & \\
Colombia, 2000 & NA & 28 \\
Dominican Republic, 1996 & $56(1858)$ & $17(5869)$ & 39 \\
Dominican Republic, 2002 & $50(1991)$ & $18(17145) 32$ \\
Haiti, 2000 & $55(2374)$ & $31(6751)$ & 24 \\
Peru, 2000 & NA & $12(18413)$ \\
\hline
\end{tabular}

NA, not available.

Numbers in parentheses are the unweighted denominators.

last 12 months, of all respondents reporting sexual activity in the last 12 months. This indicator can only be calculated from more recent surveys because earlier surveys either did not collect this data or used reference periods other than 12 months. The percentage of sexually active women reporting higher risk sex in the previous year ranges from $11 \%$ in the 1995 Uganda DHS to $31 \%$ in the 2000 Haiti DHS. Men are more likely than women to report higher risk sex in all surveys, ranging from $25 \%$ in the 2003 Zambia SBS to $56 \%$ in the 1996 Dominican Republic DHS. The gender difference in the reporting of higher risk sex in the previous year ranges from 12 percentage points in the 2003 Zambia SBS to 39 percentage points in the 1996 Dominican Republic DHS.

Trends in the percentage of respondents reporting higher risk sex in the previous 12 months are only available in Tanzania, Uganda, Zambia, and the Dominican Republic. In Tanzania there has been a large increase between the 1996 and 1999 surveys in the percentage of respondents reporting recent non-spousal, non-cohabiting partners. This may suggest either that higher risk sex has increased or that the change in questionnaire design that occurred between the two surveys may have improved reporting of non-spousal, non-cohabiting partners. Furthermore, in table 1, reporting of premarital sex in the 1996 Tanzania DHS was notably lower than in the 1991/92 and 1999 DHS surveys so it is possible that the 1996 survey was implemented in such a way as to produce lower reporting of sexual behaviour in general.

In Uganda the reporting of higher risk partnerships, especially among men, has shown little change. This finding could suggest either that behaviour in Uganda changed only slightly and questionnaire changes had little effect, or that there was actually a decline in higher risk partnerships in Uganda which is masked by improved reporting due to the move to a partial partner history questioning approach in the later survey. Premarital sexual behaviour was also fairly stable between 1995 and 2000/01 in Uganda, particularly among men, lending some support to the argument that the stable trend is genuine. More detailed analysis of the Uganda data supports the lack of change in higher risk sex in the latter part of the 1990s although there is some evidence of declines in the early 1990s and of different patterns in urban and rural areas. ${ }^{19}$ The Dominican Republic shows a similar pattern to Uganda with little change in reported higher risk sex for either men or women, consistent with the patterns observed for premarital sex.

Zambia is the only country in which trend data are available on higher risk sex from the different types of surveys. As noted for premarital sex, the DHS and SBS are fairly consistent for women and suggest a general decline in higher risk sexual behaviour. For men, the DHS obtains higher levels of higher risk sex than the SBS, resulting in an erratic male trend. However, taken separately both the DHS surveys and the SBS surveys suggest a decrease in higher risk behaviour among men. Note that, as in Uganda and the Dominican Republic, there is no evidence that the partial partner history questioning approach (used in the SBS and the 2001/02 DHS) provides higher reporting of higher risk sex than the more direct questions used in the 1996 Zambia DHS.

The analysis presented so far has shown large gender differences in reporting of both premarital sex and higher risk sex in the previous 12 months. In order to explore these differences in more detail we examine the percentage of sexually active men and women who report different partner types (table 4). Married women who report an extramarital partner in the last 12 months are less likely to report having had sex with their spouse than married men who report extramarital partners. They are also generally more likely to report having had sex with a boyfriend than married men are to report sex with a girlfriend. Reporting of casual partners is fairly similar among married men and women with any type of extramarital partner, except in Haiti. Unmarried women who admit to being sexually active are less likely than sexually active unmarried men to report casual and other partners (including commercial partners) but in some countries are more likely to report boyfriends than men are to report girlfriends. Some of these differences may reflect gender differences in the classification of partners in that women may be more likely to report a relationship as "serious" than men, but the large differences in reporting of casual partnerships suggests that unmarried women are

Table 4 Percentage of men and women with a higher risk partner in the last 12 months who report different partner types, by marital status*

\begin{tabular}{llllll}
\hline \multirow{2}{*}{$\begin{array}{l}\text { Country and partner } \\
\text { type }\end{array}$} & Married & & \multicolumn{2}{c}{ Unmarriedt } \\
\cline { 2 - 3 } \cline { 5 - 6 } \cline { 5 - 6 } & Men & Women & Men & Women \\
\hline Tanzania & $\mathrm{n}=533$ & $\mathrm{n}=146$ & $\mathrm{n}=874$ & $\mathrm{n}=649$ \\
Spouse & 95.9 & 69.2 & & 6.3 & 15.0 \\
Boy/girlfriend & 16.0 & 25.3 & & 40.5 & 52.4 \\
Casual & 78.8 & 79.5 & & 93.4 & 52.7 \\
Other & 0.0 & 0.0 & & 0.9 & 0.5 \\
Zambia & $\mathrm{n}=229$ & $\mathrm{n}=64$ & $\mathrm{n}=489$ & $\mathrm{n}=1048$ \\
Spouse & 96.9 & 87.5 & & 2.0 & 0.0 \\
Boy/girlfriend & 50.7 & 62.5 & & 73.8 & 88.5 \\
Casual & 62.0 & 56.3 & & 61.4 & 9.3 \\
Other & 4.4 & 1.6 & & 4.1 & 0.7 \\
Zimbabwe & $\mathrm{n}=168$ & $\mathrm{n}=28$ & $\mathrm{n}=600$ & $\mathrm{n}=646$ \\
Spouse & 88.1 & 75.0 & & 1.0 & 2.2 \\
Boy/girlfriend & 41.7 & 35.7 & 90.3 & 87.5 \\
Casual & 51.8 & 57.1 & & 32.1 & 21.8 \\
Other & 18.7 & 0.0 & & 12.7 & 1.6 \\
Haiti & $\mathrm{n}=408$ & $\mathrm{n}=857$ & $\mathrm{n}=919$ & $\mathrm{n}=1152$ \\
Spouse & 66.2 & 3.2 & & 0.2 & 0.5 \\
Boy/girlfriend & 68.6 & 97.1 & & 77.9 & 90.3 \\
Casual & 65.7 & 5.8 & 64.5 & 14.0 \\
Other & 3.4 & 0.0 & 3.4 & 0.2 \\
\hline
\end{tabular}

*"Higher risk" partners are defined as a non-spousal, non-cohabiting partner.

tIncludes never-married and formerly married people.

The percentages do not sum to 100 because respondents may report more than one partner type. Percentages are based on the last two or three partners in the previous 12 months depending on the questionnaire design. The number of partners asked about is consistent for men and women. 
probably underreporting such partnerships. Another possibility is that a few women are having large numbers of casual partners; however, an analysis of the distribution of reported numbers of partners in the previous 12 months failed to support this hypothesis. In addition, few men and virtually no women reported commercial sex.

\section{DISCUSSION AND CONCLUSIONS}

The objective of this paper was to review the sexual behaviour data collected to date in large population based survey programmes from the perspective of the quality of the data. The assessment of the quality of the data is limited by the fact that we do not know the "truth". We are therefore limited to assessing the internal consistency of the data and the plausibility of observed trends. A further complication is that sexual behaviour is deeply embedded in the cultural context of each population so the extent to which observed patterns reflect data quality issues versus culturally determined patterns of behaviour will vary between and within countries. Comparative analyses such as this cannot capture all the nuances of national and subnational cultural factors. Nevertheless, a comparative perspective provides insights into reporting patterns that are common across different cultural contexts and which may be indicative of potentially common instrument or reporting problems, and highlights exceptions to general patterns which require further exploration within the specific cultural context.

Premarital sex and, to some extent, higher risk sex show fluctuating trends in the sub-Saharan African countries examined. Although these patterns could be genuine, the lack of consistent trends raises concern about the quality of the data, particularly when the fluctuations are large. There are a number of data quality problems that could influence the observed trends. For example, changes in questionnaire design could affect the quality of reporting and large sampling errors could contribute to erratic fluctuations between surveys. In addition, the quality of respondents' reporting could vary over time as respondents become more or less willing to report premarital and extramarital partners, either due to wider social pressures or the quality of survey implementation.

Our analysis does not suggest large effects on the proportion who report premarital sex of removing the question to never-married women on whether they have ever had sex. Comparisons with data on childbearing, contraceptive use, and marriage collected elsewhere in the questionnaire also suggest that the observed increases in premarital sex in Latin America are genuine. This conclusion is supported by a recent detailed analysis of the reproductive behaviour of young women in Peru and Colombia. ${ }^{20}$ However, our analysis found some evidence that changes in questionnaire design and survey implementation may have significant effects on the reporting of higher risk sexual behaviour in some cases. Of particular note are large fluctuations in the reporting of premarital sex in Ghana among men and women, of premarital and higher risk sex in Tanzania, and inconsistency between the Zambia DHS and SBS surveys for men.

Another finding that raises concern about the quality of the data is the consistent and often large gender differences in the reporting of both premarital and higher risk sex. Such gender differences in reporting are common and are generally believed to be a reflection of underreporting of these behaviours by women, although other factors could also explain this pattern-including exaggeration of the number of partners by men or underrepresentation of women with a high numbers of partners (for example, commercial sex workers) in household surveys. ${ }^{58}$ Our analysis of the types of partners reported by women and men suggests that women, particularly unmarried women, probably underreport casual partners, although exaggeration of such partners by men cannot be ruled out. It also appears that married women are more likely than married men to report extramarital partners when there is no sex within the marriage, which strongly suggests that prolonged absences by husbands are linked to extramarital sex in married women. Whether this reflects genuine gender differences in behaviour or underreporting of extramarital relationships by women who are still sexually active with their spouse cannot be determined from these data.

Some earlier analyses of the quality of self-reported sexual behaviour data have used techniques such as re-interview surveys to assess reliability of responses on sexual behaviour, comparison of reported sexual behaviour with biomarkers for sexually transmitted infections, ${ }^{78}$ and comparison with less structured data collection techniques. ${ }^{4}{ }^{5}$ Such options are not available for the assessment of data presented here and the DHS and other similar surveys would benefit from more rigorous evaluation of their instruments. It would be useful to explore the feasibility of including simple experimental designs into pretests or field implementation to address certain specific concerns on instrument design or to test new developments, as was done in the 1985 pretest of the CDC Young Adult Survey in Mexico. Indeed, in DHS-I two experimental studies were undertaken in Peru and the Dominican Republic to formally test a number of new data collection approaches before introducing them into the DHS core questionnaire. ${ }^{21}{ }^{22}$ Given the likely sensitivity of reports on sexual behaviour to instrument design, and the growing convergence in question design, future changes to instruments should be evidence based and carefully evaluated.

Although it is not possible to draw definitive conclusions from the types of analyses that are possible with these data, sufficient grounds for concern exist to warrant caution in the use of survey data to monitor trends in sexual behaviour. Overall, we believe that surveys are potentially a valuable source of information on sexual behaviour, particularly given the absence of proven alternatives, but the findings must be evaluated carefully and interpreted in the context of other available information. A series of three or more surveys is needed to assess whether observed trends are plausible and differences in questionnaire design and survey implementation must be fully considered. These conclusions have implications for current efforts to monitor global HIV prevention efforts. Monitoring plans for the United Nations General Assembly Special Session on AIDS declaration, the Millennium Development Goals, and the United States Government President's Emergency Plan include indicators that require data on sexual behaviour similar to that presented here in order to calculate them (for example, condom use at last sex with a non-spousal, non-cohabiting partner; the percentage of young people aged 15-24 years who used a condom at last sexual intercourse with a non-regular sex partner). ${ }^{23}{ }^{24}$ The emphasis placed on these indicators in such global initiatives is driving demand for frequent and rapid population based data collection on sexual behaviour. Our results caution against placing heavy emphasis on short term changes in sexual behaviour between individual surveys and highlight the need for attention to quality in data collection.

\section{ACKNOWLEDGEMENTS}

The authors gratefully acknowledge the assistance of Svetlana Negroustoueva, Bernard Barrere, Noureddine Abderrahim, and Trevor Croft of ORC Macro. Funding for this paper was provided by the US Agency for International Development under the terms of Cooperative Agreement HRN-A-00-97-00018-00. The opinions expressed are those of the authors and do not necessarily reflect the views of USAID. 


\section{CONTRIBUTORS}

Sian Curtis designed and directed the study and wrote and revised the manuscript. Elizabeth Sutherland conducted data analysis, prepared tables, drafted some of the Results section, and provided comments on the draft manuscript.

\section{Authors' affiliations}

S Curtis, E Sutherland, Department of Maternal and Child Health and Carolina Population Center, University of North Carolina at Chapel Hill, NC, USA

Competing interests: Sian Curtis formerly worked for the Demographic and Health Survey Project and is currently director of the MEASURE Evaluation project which is involved in implementing the Zambia Sexual Behaviour Surveys.

\section{REFERENCES}

1 Blanc AK, Rutenberg N. Assessment of the quality of data on age at first sexual intercourse, age at first marriage, and age at first birth in the Demographic and Health Surveys. In: An assessment of DHS-I data quality. DHS methodological reports No 1, Columbia Maryland: Institute for Resource Development/Macro Systems Inc, 1990:39-79.

2 Blanc AK, Rutenberg N. Coitus and contraception: The utility of data on sexual intercourse for family planning programs. Stud Fam Plann 1991;3:162-76.

3 Gage AJ. An assessment of the quality of data on age at first union, first birth and first sexual intercourse for phase II of the Demographic and Health Surveys program. Occasional Paper No. 4, Calverton Maryland: Macro International Inc, 1995.

4 UNAIDS, WHO, MEASURE Evaluation. HIV/AIDS Prevention Indicators Survey for the General Population Aged 15-49. Field Test Reports. March 2000.

5 Dare O०, Cleland JG. Reliability and validity of survey data on sexual behaviour. Health Transit Rev 1994:4(suppl):93-110.

6 Meekers D. Immaculate conceptions in sub-Saharan Africa: Exploratory analysis of inconsistencies in the timing of first sexual intercourse and first birth. Soc Biol 1995;42:151-61.

7 Buve A, Lagarde M, Cara€l M, et al. Interpreting sexual behaviour data: validity issues in the multicentre study on factors determining the differential spread of HIV in four African cities. AIDS 2001;15(suppl 4):S117-26.

8 Nnko S, Boerma JT, Urassa M, et al. Secretive females or swaggering males? An assessment of the quality of sexual partnerships reporting in rural Tanzania. MEASURE Evaluation Working Paper No 02-57. Chapel Hill NC: Carolina Population Center, 2002.
9 Zaba B, Boerma JT, Pisani E, et al. Estimation of levels and trends in age at first sex from surveys using survival analysis. MEASURE Evaluation Working Paper No. 02-51. Chapel Hill, NC: Carolina Population Center, 2002.

10 MEASURE DHS+. Demographic and Health Surveys. Providing information for informed decisions in population, health and nutrition. Available at http:// www.measuredhs.com (accessed 26 August 2003).

11 Institute for Resource Development. Demographic and health surveys model " $A$ " questionnaire with commentary for high contraceptive prevalence countries. DHS-I Basic Documentation Number 1. Columbia, MD: Institute for Resource Development, 1987.

12 Macro International Inc. Modules for use with DHS model questionnaires. DHS-III Basic Documentation Number 8. Calverton, MD: Macro International Inc, 1996.

13 ORC Macro. DHS model " $A$ " questionnaire with commentary for high contraceptive prevalence countries. MEASURE DHS+ Basic Documentation Number 1. Calverton, MD: ORC Macro, 2001

14 Central Statistical Office (Zambia), Ministry of Health (Zambia), Project Concern International (Zambia), et al. Zambia Sexual Behaviour Survey 1998, MEASURE Evaluation Technical Reports Series. Chapel Hill, NC: Carolina Population Center, 1999.

15 Central Statistical Office (Zambia), Ministry of Health (Zambia), MEASURE Evaluation. Zambia Sexual Behaviour Survey 2000, MEASURE Evaluation Technical Reports Series. Chapel Hill, NC: Carolina Population Center, 2002.

16 UNAIDS. National AIDS Programmes: a guide to monitoring and evaluation. Geneva, Switzerland: UNAIDS/00.17E, 2000.

17 MEASURE DHS+. HIV/AIDS Survey Indicators Database. Available at http:// www.measuredhs.com (accessed 17 February 2004).

18 ORC Macro. MEASURE DHS STATcompiler. Available at http:// www.measuredhs.com (accessed 5 August 2004).

19 Uganda AIDS Commission, MEASURE Evaluation and The Republic of Uganda Ministry of Health. AIDS in Africa During the Nineties: Uganda. A review and analysis of surveys and research studies. Chapel Hill, NC: Carolina Population Center, 2003.

20 Ali M, Cleland J, Shah $\mathrm{H}$. Trends in reproductive behaviour among young single women in Colombia and Peru 1985-1999. Demography 2004; 40:659-73.

21 Goldman N, Moreno L, Westoff CF. Peru experimental study: an evaluation of fertility and child health information. Princeton, NJ and Columbia, MD: Office of Population Research, Princeton University and Institute for Resource Development/Macro Systems Inc, 1989.

22 Westoff CF, Goldman N, Moreno L. Dominican Republic experimental study: an evaluation of fertility and child health information. Princeton, $\mathrm{NJ}$ and Columbia, MD: Office of Population Research, Princeton University and Institute for Resource Development/Macro Systems Inc, 1990.

23 UNAIDS. Monitoring the declaration of commitment on HIV/AIDS: guidelines on construction of core indicators. Geneva, Switzerland: UNAIDS/02, 51E, 2002.

24 The World Bank Group. The Millennium Development Goals: About the Goals. http://www.developmentgoals.org/ (accessed 23 February 2004). 